\title{
Contribution of type 2 diabetes associated loci in the Arabic population from Tunisia: a case-control study
} Intissar Ezzidi ${ }^{\dagger 1}$, Nabil Mtiraoui* ${ }^{* 1,2}$, Stéphane Cauchi ${ }^{3}$, Emmanuel Vaillant ${ }^{3}$, Aurélie Dechaume ${ }^{3}$, Molka Chaieb ${ }^{4}$, Maha Kacem ${ }^{5}$, Wassim Y Almawi6, Philippe Froguel ${ }^{2,7}$, Touhami Mahjoub ${ }^{1}$ and Martine Vaxillaire ${ }^{3}$

\begin{abstract}
Address: ${ }^{1}$ Research Unit of Biology and Genetics of Hematological and Auto-immune diseases, Faculty of Pharmacy of Monastir, University of Monastir, Monastir, Tunisia, ${ }^{2}$ Higher Institute of Biotechnology of Monastir, University of Monastir, Monastir, Tunisia, ${ }^{3} \mathrm{Genomics}$ and Molecular Physiology of Metabolic Diseases, CNRS, 8090-Lille Institute of Biology, Pasteur Institute, Lille, France, ${ }^{4}$ Endocrinology and Diabetic Service, CHU Farhat Hached of Sousse, Tunisia, ${ }^{5}$ Nephrology and Internal Medicine Service, CHU Fatouma Bourguiba, Monastir, Tunisia, ${ }^{6}$ Department of Medical Biochemistry, Arabian Gulf University, Manama, Bahrain and ${ }^{7}$ Genomic Medicine, Hammersmith Hospital, Imperial College, London, England, UK

Email: Intissar Ezzidi - intissar_z@yahoo.fr; Nabil Mtiraoui* - mtiraouinabil@yahoo.fr; Stéphane Cauchi - Stephane.Cauchi@good.ibl.fr; Emmanuel Vaillant - emmanuel.vaillant@good.ibl.fr; Aurélie Dechaume - aurelie.dechaume@good.ibl.fr;

Molka Chaieb - molkachadli@yahoo.fr; Maha Kacem - kacem_maha@yahoo.fr; Wassim Y Almawi - wyalmawi@yahoo.co.uk; Philippe Froguel - P.Froguel@imperial.ac.uk; Touhami Mahjoub - mahjoubtouhami@yahoo.fr;

Martine Vaxillaire - martine.vaxillaire@good.ibl.fr

* Corresponding author †Equal contributors
\end{abstract}

Published: 15 April 2009

BMC Medical Genetics 2009, 10:33 doi:10.1186/147I-2350-10-33
Received: 5 November 2008

Accepted: 15 April 2009

This article is available from: http://www.biomedcentral.com/I47I-2350/I0/33

(C) 2009 Ezzidi et al; licensee BioMed Central Ltd.

This is an Open Access article distributed under the terms of the Creative Commons Attribution License (http://creativecommons.org/licenses/by/2.0), which permits unrestricted use, distribution, and reproduction in any medium, provided the original work is properly cited.

\begin{abstract}
Background: Candidate gene and genome-wide association studies have both reproducibly identified several common Single Nucleotide Polymorphisms (SNPs) that confer type 2 diabetes (T2D) risk in European populations. Our aim was to evaluate the contribution to T2D of five of these established T2D-associated loci in the Arabic population from Tunisia.

Methods: A case-control design comprising 884 type 2 diabetic patients and 513 control subjects living in the East-Center of Tunisia was used to analyze the contribution to T2D of the following SNPs: E23K in KCNJI I/Kir6.2, KI2IQ in ENPPI, the -30G/A variant in the pancreatic $\beta$-cell specific promoter of Glucokinase, rs7903/46 in TCF7L2 encoding transcription factor 7-like2, and rs7923837 in HHEX encoding the homeobox, hematopoietically expressed transcription factor.

Results: TCF7L2-rs7903।46 T allele increased susceptibility to T2D (OR $=1.25$ [1.06-I.47], $P=$ 0.006 ) in our study population. This risk was $56 \%$ higher among subjects carrying the TT genotype in comparison to those carrying the $C C$ genotype $(O R=1.56[1.13-2.16], P=0.002)$. No allelic or genotypic association with T2D was detected for the other studied polymorphisms.

Conclusion: In the Tunisian population, TCF7L2-rs7903।46 T allele confers an increased risk of developing T2D as previously reported in the European population and many other ethnic groups. In contrast, none of the other tested SNPs that influence T2D risk in the European population was associated with T2D in the Tunisian Arabic population. An insufficient power to detect minor allelic contributions or genetic heterogeneity of T2D between different ethnic groups can explain these findings.
\end{abstract}




\section{Background}

T2D is a complex metabolic disorder which is caused by both decreased insulin sensitivity, and impaired insulin secretion due to pancreatic $\beta$-cell defects [1]. T2D is thought to result from the effects of environmental and lifestyle risk factors together with at-risk genetic variants in predisposed individuals [2].

T2D is a global major health problem showing worldwide increasing prevalence [3]. The Arabic population is however particularly targeted by $\mathrm{T} 2 \mathrm{D}[4,5]$. In the Tunisian population, the prevalence of $\mathrm{T} 2 \mathrm{D}$ reaches $9 \%$ of adults [6] that is much higher compared with European populations and may be due to the specificity of the Tunisian life style or to a specific genetic background.

From the previous familial linkage and candidate-gene studies, T2D-associated single nucleotide polymorphisms (SNPs) have been confirmed and widely replicated, but with modest effects on disease risk $[7,8]$. These variants include the E23K variation in KCNJ11, encoding the Kir6.2 subunit of the $\mathrm{K}^{+}$-ATP channel [9], the Pro12Ala variant in PPARG [10], the -30G/A polymorphism in the $\beta$-cell specific promoter of glucokinase (GCK) $[8,11]$, and the K121Q variant of ENPP1 encoding ectonucleotide pyrophosphatase phosphodiesterase, the inhibitor of insulin receptor [12].

The SNP with the largest risk effect is the intronic variant, rs7903146, in the TCF7L2 locus $[13,14]$. This association was consistently replicated in populations of various ethnic origins, among which Morrocans [15].

Recently, genome-wide association (GWA) studies revealed novel SNPs that increased T2D risk in different European populations [14,16-18]. The French GWA study detected unexpected association to T2D for non-coding SNPs at the HHEX locus (homeobox, hematopoietically expressed) [14], which were also shown to contribute to an increased risk of T2D in British [18], Japanese [19] and other Asiatic [20] populations.

In this study, we analyzed five polymorphisms in the following genes, rs7903146 of TCF7L2, rs7923837 of HHEX, rs1788994 of GCK, rs5219 of KCNJ11/Kir6.2 and rs1044498 of ENPP1 using a case-control design in 1,397 individuals ( 884 unrelated T2D patients and 513 normoglycemic controls) to assess their association with T2D risk in the Tunisian population. To our knowledge, four of them have not been previously tested in this Arabic population, and we aim to evaluate whether these common variants reported to be at-risk for T2D in European populations may also contribute to T2D risk and aetiology in the Tunisian population living in the East-Center part of the country.

\section{Methods \\ Study population}

The T2D group includes 884 unrelated Tunisian diabetic subjects (406 males, 478 females). The affected individuals were recruited in 2003-2006 in collaboration with the Endocrinology-Diabetology departments of Farhat Hached Hospital (Sousse, Tunisia) and Fattouma Bourguiba University Hospital (Monastir, Tunisia). T2D was defined according to 1997 American Diabetes Association. Inclusion criteria: fasting plasma glucose $\geq 7.0$ $\mathrm{mmol} / \mathrm{l}$ and/or treatment for diabetes included diet and/ or oral antidiabetic drugs and/or insulin to achieve glycemic control. All subjects who required insulin had been treated with oral drugs for at least 2 years.

The diabetic cases included in the study are representative of the diabetic population examined in two hospital clinics in the center of Tunisia (Sousse and Monastir, Tunisia) within a time period of 4 years; no clinical criteria of exclusion have been held (except patients diagnosed with type 1 diabetes, and patients with type 2 diabetes diagnosed at age $\leq 40$ years).

Individual and clinical characteristics were recorded for all subjects, including age at examination, gender, age at diagnosis, duration of diabetes, first-degree family history of diabetes, treatment for diabetes including date of initiation and/or discontinuation of oral agents or insulin. When available, the following details were obtained from the clinic records: dyslipidaemia, history of chronic complications of diabetes, history of hypertension, ischaemic heart disease and other medical illness.

All T2D patients were compared to a group of 513 normoglycaemic subjects (fasting glycaemia $<6.1 \mathrm{mmol} / \mathrm{l}$, age at examination $>45$ years, BMI $<30 \mathrm{~kg} / \mathrm{m}^{2}$ ) from blood donors recruited in the transfusion centres of Monastir and Sousse (Center of Tunisia). None was first degree relative of other subjects in the case or control groups; they were not known to have diabetes although occult disease was not excluded.

Written informed consent was obtained from all subjects and DNA was extracted using the standard phenol-chloroform procedure. The study protocol was approved by the University of Monastir (Tunisia).

\section{SNP genotyping}

SNP genotyping of rs7903146 in TCF7L2, rs7923837 in HHEX and rs1799884 in GCK promoter were performed using allelic discrimination TaqMan SNP Genotyping Assays (Applied Biosystems, Foster City, California. USA). The PCR primers and TaqMan probes were designed by Primer Express and optimized according to the manufacturer's protocol. We obtained a 95\% genotyping success 
rate (except for HHEX rs7923837 which gave a 90\% genotyping rate). A random of $10 \%$ sample set was re-tested with the same method to confirm genotype accuracy. No difference of genotypes was found between the duplicate samples.

For genotyping of E23K (rs5219) in KCNJ11/Kir6.2 and K121Q (rs1044498) in ENPP1, we used the FRET technology using the Light Cycler TM assay (Roche Diagnostics, Basel, Switzerland). For both SNPs, the genotyping success rate was $91 \%$. In order to assess genotyping accuracy for these two SNPs, 20 random samples were tested by direct sequencing, which provided a $100 \%$ concordance rate.

\section{Statistical analysis}

Allele frequencies were calculated by the genotype-counting method, and each polymorphism was tested for Hardy-Weinberg equilibrium using Chi square goodnessof-fit test using HPlus 2.5 software (see Additional file 1). Comparison of allele frequencies and genotype distributions between all T2D and control groups were done using the Pearson's Chi square test.

Genotypic associations for additive, dominant and recessive models were tested by calculating a logistic regression (adjustments) statistic and corresponding $P$ value using the program SNPstats http://bioinfo.iconcologia.net/ index.php? module $=$ Snpstats. The results are expressed as $P$ value (two-tailed), odds ratio (OR) and $95 \%$ confidence intervals (CI). The minimum detectable effect size with a statistical power of $80 \%$ was assessed [21] using Quanto software v.1.2.3 http://hydra.usc.edu/GxE.

Student's t-test, used to determine differences in means of continuous variables in the normoglycemic control subjects, was performed using the SPSS statistical analysis software v.16.0 (SPSS, Chicago, Illinois, USA). Statistical significance was set at a $P$-value $<0.05$.

\section{Results}

The clinical characteristics of the T2D patients and control subjects are given in Table 1. Among T2D subjects, $30.09 \%(\mathrm{n}=266)$ are obese $\left(\mathrm{BMI} \geq 30 \mathrm{~kg} / \mathrm{m}^{2}\right)$ versus $69.91 \%(\mathrm{n}=618)$ non-obese $\left(\mathrm{BMI}<30 \mathrm{~kg} / \mathrm{m}^{2}\right)$. No significant differences in clinical features were noted when all T2D patients were compared to the non-obese T2D group (data not shown).

The distribution of allelic and genotypic frequencies of the five SNPs was compared between the two study groups (884 T2D cases and 513 normoglycemic controls) (Table 2 ). The genotype distributions of all SNPs obeyed Hardy Weinberg equilibrium in the control group (Supplementary Table).

The T allele of TCF7L2 was significantly associated with increased risk of T2D and the OR adjusted for age, gender and BMI was $1.25,95 \%$ IC [1.06-1.47], $P=0.006$ (Table 2 ). The association was observed in all genotypic models but the highest risk was observed under the additive model $(\mathrm{OR}=1.56,95 \%$ IC $[1.13-2.16], P=0.002)$ (Table 2).

As shown in Table 2, no other alleles of the remaining variants were associated with an increased risk of T2D in the Tunisian population.

We estimated the minimum effect sizes detectable with a statistical power of $80 \%$ under different genetic models, and according to the allelic frequencies of each SNP tested in our study, as indicated in Table 3. Except for TCF7L2 SNP that showed a significant effect on T2D risk with an additive OR value above the threshold estimated in our

Table I: Characteristics of the T2D patients and control subjects from the Tunisian population

\begin{tabular}{lll}
\hline Characteristics & Controls $(\mathbf{n}=\mathbf{5} \mathbf{~ I})$ & T2D $(\mathbf{n}=\mathbf{8 8 4})$ \\
\hline Gender (Male/Female) & $258 / 255$ & $406 / 478$ \\
Age at examination (years) & $60 \pm 8.69$ & $59.42 \pm 11.09$ \\
Mean BMI (kg/m2) & $24.83 \pm 2.73$ & $27.82 \pm 5.30$ \\
Systolic blood pressure (mmHg) & $122.12 \pm 14.33$ & $139.80 \pm 28.13$ \\
Diastolic blood pressure (mmHg) & $78.18 \pm 10.55$ & $80.92 \pm 12.73$ \\
Fasting glucose (mmol/l) & $5.05 \pm 0.64$ & $12.67 \pm 5.30$ \\
HbAlc (\%) & $4.47 \pm 1.23$ & $9.49 \pm 3.89$ \\
Total cholesterol (mmol/l) & $4.64 \pm 1.28$ & $5.26 \pm 1.42$ \\
Triglycerides (mmol/l) & $1.18 \pm 0.60$ & $1.77 \pm 1.31$ \\
HDL-cholesterol (mmol/l) & $1.27 \pm 0.39$ & $1.07 \pm 0.38$ \\
LDL-cholesterol (mmol/l) & $2.59 \pm 1.60$ & $3.77 \pm 1.37$
\end{tabular}

$\mathrm{n}$ : number of total subjects

Data are expressed as means \pm SD.

Most of the diabetic patients included in the study were recruited immediately after their admission to the Endocrinology Department, explaining a poor control of glycemic levels (mean fasting glucose: $12.67 \mathrm{mmol} / \mathrm{l}$; mean HbAlc: $9.49 \%$ ) in these subjects. 
Table 2: T2D association for candidate SNPs in the Tunisian study sample of 1,397 individuals

\begin{tabular}{|c|c|c|c|c|c|c|c|c|}
\hline Gene SNP & Genotype & Control/T2D & $\begin{array}{l}\text { Additive model' } \\
\text { OR }(95 \% \mathrm{Cl})\end{array}$ & $\boldsymbol{P}^{\dagger}$ & $\begin{array}{c}\text { Dominant model }{ }^{2} \\
\text { OR }(95 \% \mathrm{Cl})\end{array}$ & $\boldsymbol{P} \ddagger$ & $\begin{array}{l}\text { Recessive model }^{3} \\
\text { OR }(95 \% \mathrm{Cl})\end{array}$ & $\mathbf{P}^{*}$ \\
\hline \multirow[t]{5}{*}{ TCF7L2 rs7903।46 } & $\mathrm{n}$ & $511 / 863$ & & & & & & \\
\hline & $C C(1 / 1)$ & $181 / 250$ & & & & & & \\
\hline & $\mathrm{CT}(\mathrm{I} / 2)$ & $235 / 396$ & $1.24(0.95-1.61)$ & 0.135 & & & & \\
\hline & $\mathrm{TT}(2 / 2)$ & $95 / 217$ & $1.56(1.13-2.16)$ & 0.002 & $1.33(1.04-1.70)$ & 0.023 & $1.38(1.04-1.83)$ & 0.025 \\
\hline & $\operatorname{MAF}(\mathrm{T})$ & $0.42 / 0.48$ & $1.25(1.06-1.47)$ & $0.006 \#$ & & & & \\
\hline \multirow[t]{5}{*}{ KCNJII rs5219 } & $\mathrm{n}$ & $503 / 805$ & & & & & & \\
\hline & $\mathrm{CC}(\mathrm{I} / \mathrm{I})$ & $250 / 371$ & & & & & & \\
\hline & CT $(1 / 2)$ & $213 / 352$ & $1.03(0.80-1.31)$ & 0.399 & & & & \\
\hline & TT $(2 / 2)$ & $40 / 82$ & $1.23(0.80-1.90)$ & 0.148 & $1.06(0.84-1.34)$ & 0.630 & I.22 (0.80-I.85) & 0.360 \\
\hline & $\operatorname{MAF}(\mathrm{T})$ & $0.29 / 0.32$ & $1.07(0.90-1.29)$ & $0.440^{\#}$ & & & & \\
\hline \multirow[t]{5}{*}{ GCKrsI 799884} & $\mathrm{n}$ & $505 / 865$ & & & & & & \\
\hline & GG $(1 / I)$ & $324 / 552$ & & & & & & \\
\hline & $\mathrm{GA}(1 / 2)$ & $157 / 272$ & $1.01(0.79-1.30)$ & 0.939 & & & & \\
\hline & $\mathrm{AA}(2 / 2)$ & $24 / 41$ & $1.20(0.69-2.08)$ & 0.902 & $1.03(0.81-1.32)$ & 0.780 & $1.20(0.70-2.05)$ & 0.510 \\
\hline & $\operatorname{MAF}(\mathrm{A})$ & $0.20 / 0.20$ & $1.04(0.86-1.28)$ & $0.640 \#$ & & & & \\
\hline \multirow[t]{5}{*}{ HHEXrs7923837 } & $\mathrm{n}$ & $504 / 795$ & & & & & & \\
\hline & GG $(I / I)$ & $271 / 448$ & & & & & & \\
\hline & $\mathrm{GA}(1 / 2)$ & $200 / 292$ & $0.88(0.69-1.13)$ & 0.661 & & & & \\
\hline & $\mathrm{AA}(2 / 2)$ & $33 / 55$ & $0.97(0.60-1.58)$ & 0.934 & $0.89(0.70-1.13)$ & 0.340 & $1.03(0.64-1.65)$ & 0.910 \\
\hline & $\operatorname{MAF}(\mathrm{A})$ & $0.26 / 0.25$ & $0.93(0.77-1.13)$ & $0.470 \#$ & & & & \\
\hline \multirow[t]{5}{*}{ ENPPI rsI044498 } & $n$ & $499 / 809$ & & & & & & \\
\hline & $\mathrm{AA}(\mathrm{I} / \mathrm{I})$ & $228 / 402$ & & & & & & \\
\hline & $A C(1 / 2)$ & $205 / 311$ & $0.86(0.67-1.12)$ & 0.243 & & & & \\
\hline & $\mathrm{CC}(2 / 2)$ & $66 / 96$ & $0.78(0.54-1.14)$ & 0.326 & $0.84(0.66-1.07)$ & 0.160 & $0.84(0.59-1.19)$ & 0.320 \\
\hline & $\operatorname{MAF}(\mathrm{C})$ & $0.33 / 0.31$ & $0.88(0.74-1.04)$ & $0.140 \#$ & & & & \\
\hline
\end{tabular}

$\mathrm{n}$ : number of total subjects, MAF: Minor allele frequency,,$+ \neq, *$ Genotype specific $P$ values and OR are adjusted for age gender and BMI in each additive, dominant or recessive genetic model, respectively. \#Allele-specific $P$ values and OR of the log-additive genetic model are adjusted for age, gender and BMI.

I Genetic additive model: I/I vs. $1 / 2$ or $2 / 2$ genotypes

2 Genetic dominant model: $1 / /$ vs. $1 / 2+2 / 2$ genotypes

3 Genetic recessive model: $1 / 1+1 / /$ vs. $2 / 2$ genotypes

power calculation, the other four SNPs are known to have a lower allelic contribution that could not be easily detectable in this middle-sized cohort (Table 3 ).

\section{Discussion}

The T-allele of TCF7L2-rs7903146 is associated with an increased risk in T2D among the Tunisian population. Recent GWA studies in populations of European descent showed that TCF7L2 is the T2D gene having the largest risk effect to date $[14,22]$, even if the causative variant(s) and etiological mechanism(s) are not yet completely characterized [23]. Our data are also in agreement with the numerous previous replications of the TCF7L2-associated SNPs mostly in white Europeans, but also in West Africans, Mexican and African Americans, Indians and Japanese populations $[13,15,24]$. The rs7903146 variant was also associated with an increased risk in T2D in Moroccan subjects, suggesting a similar effect in several North Afri- can populations [15]. However, a recent study of TCF7L2 variants in an Arab population of Saudi origin reported no association with T2D upon analysis of two SNPs (including rs7903146) [25].

With regard to the remaining four loci, no association with T2D was detected for HHEX, GCK, KCNJ11 and ENPP1 variants, whereas previous independent studies reported such associations with T2D risk in several European white populations $[9,14,26,27]$. However, a lack of association between SNPs at the HHEX locus and T2D was also reported in a Moroccan population [27].

Minor allele frequencies of the SNPs examined in this study compared to those reported from several other populations with different ethnic backgrounds appeared to be variable depending on ethnicity. For example, the frequency of the Q121 allele in our study population is 
Table 3: Minimum effect size detected with a statistical power of $80 \%$ in the study sample

\begin{tabular}{|c|c|c|c|c|}
\hline Gene name & SNP rs ID & $\begin{array}{l}\text { Additive model } \\
\text { OR (T2D) }\end{array}$ & $\begin{array}{l}\text { Dominant model } \\
\text { OR (T2D) }\end{array}$ & $\begin{array}{l}\text { recessive model } \\
\text { OR (T2D) }\end{array}$ \\
\hline TCF7L2 & rs7903|46 & 1.25 & 1.44 & 1.43 \\
\hline KCNJII & rs5219 & 1.26 & 1.37 & 1.62 \\
\hline GCK & rsl799884 & 1.31 & 1.38 & 2.05 \\
\hline HHEX & rs7923837 & 1.30 & 1.40 & 1.80 \\
\hline ENPPI & rs 1044498 & 1.27 & 1.37 & 1.64 \\
\hline
\end{tabular}

The estimation of the risk effects (OR) with a statistical power of $80 \%$ was assessed using the Quanto software.

T2D: Type 2 diabetes

higher (31\%) than the one reported in Caucasians which ranged from 10 to $17 \%[12,28]$, but relatively lower than the one observed in another Tunisian cohort living in the north of the country (47\%) [29], or in African Americans $(78,5 \%)[30]$.

The extensively studied K121Q variant (rs1044498) in ENPP1 did not reveal evidence for association with T2D in our study from the Tunisian population. The contribution of this variant to T2D risk in the European white populations has been established in several $[12,31]$ but not all $[32,28]$ studies. These findings question the reproducibility of a real contribution to T2D risk and emphazise the more complex diabesity component.

A recent study in another Tunisian population reported that the ENPP1-K121Q variant may predispose to T2D (with an OR of 1.89, 95\%CI [1.13-3.15], under a dominant model) [29], but the smaller sample size and ascertainment of the diabetic patients analyzed could explain this difference. In addition, it is noteworthy that in our study we investigated a multicentric sample of T2D patients, more representative of the Tunisian general population contrary to the study by Bouhaha et al. which investigated only a group of individuals from the north of Tunisia. In this part of country, people life style's is more westernized with reduced physical activity and excessive calorie intake in foods. Otherwise, these divergent results of association, whereas a similar frequency of the Q-121 allele was observed in both studies, could be explained by a modest contribution of the ENPP1-K121Q variant to the risk of T2D in Tunisians at the population level, and also in interaction with BMI and environmental factors in modulating T2D risk, as previously reported [33].

We have to note that the present study was underpowered to demonstrate an effect in T2D risk for HHEX, GCK, KCNJ11 or ENPP1 variants similar to those previously reported from the European diabetic cohorts $[27,30,34]$. Indeed, more modest genetic effects in a polygenic context will need analysis of a larger sample size to be able to definitely conclude for a lack of association due to genetic heterogeneity between specific ethnic backgrounds or to other confounding factors, or to an underpowered association study.

It was previously demonstrated that the genetic effects of variants associated with either insulin secretion (like for GCK, KCNJ11 or TCF7L2) or insulin action (for ENPP1, ADIPOQ or PPARG) may be modulated by the obesity status or adiposity $[9,12,26,28,32,34]$. Thus, the impact on T2D risk may be largely different in obese and non obese individuals depending on the gene variant, as this was exemplified in adequately designed studies $[12,26,28,34]$.

Previous genetic studies undertaken in this case-control study from the Tunisian population have assessed the impact of a number of gene variants on T2D risk and vascular complications, such as PPARG [35], eNOS [36], MTHFR [37], IL-10 [38]. Except to the Pro12Ala variants of PPARG which were found to be associated only to a lower BMI among T2D patients, the other variants showed a contribution to T2D and in part to diabetic vascular complications.

\section{Conclusion}

In conclusion, our data support an effect of the widely replicated TCF7L2 variant on T2D risk in the Arabic population from Tunisia, whereas the other variants tested were not found to play a major role in T2D. In comparison to the European and non-European populations, these findings can be explained by several factors, such as a minor contribution of the studied variants that is not detectable in this middle-sized cohort, the presence of Arabic-specific SNPs in some loci, or a genetic heterogeneity of T2D between different ethnic groups, which we already highlighted in a recent study of novel T2D-associated SNPs in several populations of different ethnic origins [27]. In this context, further GWA studies in Arabic populations from Maghreb are required to further define the genetic components of T2D in these populations.

\section{Abbreviations}

BMI: Body Mass Index; CI: Confidence interval; $\mathrm{K}^{+}$-ATP channel: ATP-sensitive potassium channel; MAF: Minor Allele Frequency; OR: Odds ratio; PCR: Polymerase Chain 
Reaction; SNP: Single Nucleotide Polymorphism; T2D: Type 2 Diabetes.

\section{Competing interests}

The authors declare that they have no competing interests.

\section{Authors' contributions}

IE and NM participated in the design of the study, carried out the SNP genotyping and the analyses of the genotype data, and contributed to the statistical analyses and the drafting of the manuscript. SC contributed to the statistical analyses and participated in the writing of the manuscript. EV participated in the SNP genotyping and some of the genetic analyses. AD carried out some of the genotyping experiments. MC and $\mathrm{MK}$ coordinated the patients' recruitment. WYA, PF and TM contributed to the manuscript editing. MV contributed to the design and coordination of the study, to the genetic analyses and drafted the manuscript. All authors read and approved the final manuscript.

\section{Additional material}

\section{Additional file 1}

Supplemental table. Test of Hardy-Weinberg equilibrium for each SNP genotyped in the control and T2D study subjects.

Click here for file

[http://www.biomedcentral.com/content/supplementary/14712350-10-33-S1.doc]

\section{Acknowledgements}

This work was supported by grants from «La direction générale de la recherche scientifique et de la renovation technologique») (UR05ES03; DGRST, Tunisie) and «coopération française» (CMCU-2008; code: 08G0819).

The authors gratefully acknowledge the members of the Endocrinology and Internal Medicine departments at Sousse and Monastir University Hospitals, who contributed to the patient's recruitment. We are also grateful to Marianne Deweider and Frédéric Allegaert who are in charge of the DNA bank management at the CNRS UMR8090 laboratory in Lille, France, and to all subjects who participated to this study.

\section{References}

I. Stumvoll M, Goldstein BJ, van Haeften TW: Type 2 diabetes: principles of pathogenesis and therapy. Lancet 2005, 365(9467): 1333-1346.

2. Permutt MA, Wasson J, Cox N: Genetic epidemiology of diabetes. J Clin Invest 2005, I I 5(6): I 43 I- I 439.

3. Zimmet $P$, Alberti $K G$, Shaw J: Global and societal implications of the diabetes epidemic. Nature 200I, 4 I 4(6865):782-7.

4. al-Mahroos F, McKeigue PM: High prevalence of diabetes in Bahrainis. Associations with ethnicity and raised plasma cholesterol. Diabetes Care 1998, $21: 936-942$

5. Al-Futaisi A, Al-Zakwani I, Almahrezi A, et al.: Prevalence and predictors of microalbuminuria in patients with type 2 diabetes mellitus: a cross-sectional observational study in Oman. Diabetes Res Clin Pract 2006, 72:212-215.
6. Bouguerra R, Alberti H, Salem LB, Rayana CB, Atti JE, Gaigi S, Slama $C B$, Zouari $B$, Alberti $K$ : The global diabetes pandemic: the Tunisian experience. Eur J Clin Nutr 2007, 6 I (2):160-5.

7. Weedon MN, McCarthy MI, Hitman G, Walker M, Groves CJ, Zeggini E, Rayner NW, Shields B, Owen KR, Hattersley AT, et al.: Combining information from common type 2 diabetes risk polymorphisms improves disease prediction. PLoS Med 2006, 3(10):e374.

8. Vaxillaire M, Veslot J, Dina C, Proenca C, Cauchi S, Charpentier G, Tichet J, Fumeron F, Marre M, Meyre D, et al.: Impact of common type 2 diabetes risk polymorphisms in the DESIR prospective study. Diabetes 2008, 57(I):244-254.

9. Nielsen EM, Hansen L, Carstensen B, Echwald SM, Drivsholm T, Glumer C, Thorsteinsson B, Borch-Johnsen K, Hansen T, Pedersen O: The E23K variant of Kir6.2 associates with impaired postOGTT serum insulin response and increased risk of type 2 diabetes. Diabetes 2003, 52(2):573-577.

10. Altshuler D, Hirschhorn JN, Klannemark M, Lindgren CM, Vohl MC, Nemesh J, Lane CR, Schaffner SF, Bolk S, Brewer C, et al.: The common PPARgamma Prol2Ala polymorphism is associated with decreased risk of type 2 diabetes. Nat Genet 2000, 26(I):76-80.

II. Winckler W, Weedon MN, Graham RR, McCarroll SA, Purcell S, Almgren P, Tuomi T, Gaudet D, Bostrom KB, Walker M, et al.: Evaluation of common variants in the six known maturity-onset diabetes of the young (MODY) genes for association with type 2 diabetes. Diabetes 2007, 56(3):685-693.

12. Meyre D, Bouatia-Naji N, Tounian A, Samson C, Lecoeur C, Vatin V, Ghoussaini M, Wachter C, Hercberg S, Charpentier G, et al.: Variants of ENPPI are associated with childhood and adult obesity and increase the risk of glucose intolerance and type 2 diabetes. Nat Genet 2005, 37(8):863-867.

13. Grant SF, Thorleifsson G, Reynisdottir I, Benediktsson R, Manolescu A, Sainz J, Helgason A, Stefansson H, Emilsson V, Helgadottir A, et al: Variant of transcription factor 7-like 2 (TCF7L2) gene confers risk of type 2 diabetes. Nat Genet 2006, 38(3):320-323.

14. Sladek R, Rocheleau G, Rung J, Dina C, Shen L, Serre D, Boutin P, Vincent $D$, Belisle A, Hadjadj S, et al: A genome-wide association study identifies novel risk loci for type 2 diabetes. Nature 2007, 445(7 I 30):88I-885.

15. Cauchi S, El Achhab Y, Choquet H, Dina C, Krempler F, Weitgasser $R$, Nejjari C, Patsch W, Chikri M, Meyre D, et al.: TCF7L2 is reproducibly associated with type 2 diabetes in various ethnic groups: a global meta-analysis. J Mol Med 2007, 85(7):777-782.

16. Steinthorsdottir V, Thorleifsson G, Reynisdottir I, Benediktsson R, Jonsdottir T, Walters GB, Styrkarsdottir U, Gretarsdottir S, Emilsson $\mathrm{V}$, Ghosh S, et al.: A variant in CDKALI influences insulin response and risk of type 2 diabetes. Nat Genet 2007, 39(6):770-775.

17. Scott LJ, Mohlke KL, Bonnycastle LL, Willer CJ, Li Y, Duren WL, Erdos MR, Stringham HM, Chines PS, Jackson AU, et al.: A genomewide association study of type 2 diabetes in Finns detects multiple susceptibility variants. Science 2007, 316(5829): $134 \mid-1345$.

18. Zeggini E, Weedon MN, Lindgren CM, Frayling TM, Elliott KS, Lango $H$, Timpson NJ, Perry JR, Rayner NW, Freathy RM, et al:: Replication of genome-wide association signals in UK samples reveals risk loci for type 2 diabetes. Science 2007, 3 I 6(5829): I 336-I3.

19. Horikoshi M, Hara K, Ito C, Shojima N, Nagai R, Ueki K, Froguel P, Kadowaki T: Variations in the HHEX gene are associated with increased risk of type 2 diabetes in the Japanese population. Diabetologia 2007, 50( I 2):246I-2466.

20. Ng MC, Park KS, Oh B, Tam CH, Cho YM, Shin HD, Lam VK, Ma RC, So WY, Cho YS, et al.: Implication of genetic variants near TCF7L2, SLC30A8, HHEX, CDKALI, CDKN2A/B, IGF2BP2, and FTO in type 2 diabetes and obesity in 6,719 Asians. Diabetes 2008, 57(8):2226-2233.

21. Gauderman WJ: Sample size requirements for association studies of gene-gene interaction. Am J Epidemiol 2002, I 55(5):478-84.

22. Perry JR, Frayling TM: New gene variants alter type $\mathbf{2}$ diabetes risk predominantly through reduced beta-cell function. Curr Opin Clin Nutr Metab Care 2008, I I (4):37I-377.

23. Cauchi S, Froguel P: TCF7L2 genetic defect and type 2 diabetes. Curr Diab Rep 2008, 8(2): 149-1 55. 
24. Lewis JP, Palmer ND, Hicks PJ, Sale MM, Langefeld CD, Freedman BI, Divers J, Bowden DW: Association analysis in african americans of European-derived type 2 diabetes single nucleotide polymorphisms from whole-genome association studies. Diabetes 2008, 57(8):2220-2225.

25. Alsmadi O, Al-Rubeaan K, Mohamed G, Alkayal F, Al-Saud H, Al-Saud NA, Al-Daghri N, Mohammad S, Meyer BF: Weak or no association of TCF7L2 variants with Type 2 diabetes risk in an Arab population. BMC Med Genet 2008, 9:72.

26. Rose CS, Ek J, Urhammer SA, Glumer C, Borch-Johnsen K, Jorgensen T, Pedersen O, Hansen T: A -30G >A polymorphism of the betacell-specific glucokinase promoter associates with hyperglycemia in the general population of whites. Diabetes 2005, 54(10):3026-303I.

27. Cauchi S, Meyre D, Durand E, Proenca C, Marre M, Hadjadj S, Choquet $\mathrm{H}$, De Graeve F, Gaget S, Allegaert F, et al.: Post genome-wide association studies of novel genes associated with type $\mathbf{2}$ diabetes show gene-gene interaction and high predictive value. PLOS ONE 2008, 3(5):e203I.

28. Grarup N, Urhammer SA, Ek J, Albrechtsen A, Glumer C, BorchJohnsen K, Jorgensen T, Hansen T, Pedersen O: Studies of the relationship between the ENPPI KI I IQ polymorphism and type 2 diabetes, insulin resistance and obesity in 7,333 Danish white subjects. Diabetologia 2006, 49(9):2097-2104.

29. Bouhaha R, Meyre D, Kamoun HA, Ennafaa H, Vaillant E, Sassi R, Baroudi T, Vatin V, Froguel P, Elgaaied A, Vaxillaire M: Effect of ENPPI/PC-I-KILIQ and PPARgamma-ProI2Ala polymorphisms on the genetic susceptibility to T2D in the Tunisian population. Diabetes Res Clin Pract 2008, 8 I (3):278-83.

30. Chandalia M, Grundy SM, Adams-Huet B, Abate N: Ethnic differences in the frequency of ENPPI/PCI I I I genetic variant in the Dallas heart study cohort. J Diabetes Complications 2007, 21:143-8.

31. McAteer JB, Prudente S, Bacci S, Lyon HN, Hirschhorn JN, Trischitta V, Florez JC: The ENPPI KIIIQ polymorphism is associated with type 2 diabetes in European populations: evidence from an updated meta-analysis in $\mathbf{4 2 , 0 4 2}$ subjects. Diabetes 2008 , 57(4): II $125-1 \mid 130$.

32. Lyon HN, Florez JC, Bersaglieri T, Saxena R, Winckler W, Almgren P, Lindblad U, Tuomi T, Gaudet D, Zhu X, Cooper R, Ardlie KG, Daly MJ, Altshuler D, Groop L, Hirschhorn JN: Common variants in the ENPPI gene are not reproducibly associated with diabetes or obesity. Diabetes 2006, 55(I I):3|80-3I84.

33. Matsuoka N, Patki A, Tiwari HK, Allison DB, Johnson SB, Gregersen PK, Leibel RL, Chung WK: Association of K $121 \mathrm{Q}$ polymorphism in ENPPI (PC-I) with BMI in Caucasian and African-American adults. Intl J Obes 2006, 30(2):233-237.

34. Cauchi S, Nead KT, Choquet H, Horber F, Potoczna N, Balkau B, Marre M, Charpentier G, Froguel P, Meyre D: The genetic susceptibility to type 2 diabetes may be modulated by obesity status: implications for association studies. BMC Med Genet 2008, 9:45.

35. Mohamed MB, Mtiraoui N, Ezzidi I, Chaieb M, Mahjoub T, Almawi WY: Association of the peroxisome proliferator-activated receptor-gamma2 ProI2Ala but not the CI43 IT gene variants with lower body mass index in Type 2 diabetes. J Endocrinol Invest 2007, 30(I I):937-43.

36. Ezzidi I, Mtiraoui N, Mohamed MB, Mahjoub T, Kacem M, Almawi WY: Association of endothelial nitric oxide synthase Glu298Asp, 4b/a, and -786T $>C$ gene variants with diabetic nephropathy. J Diabetes Complications 2008, 22(5):33I-8.

37. Mtiraoui N, Ezzidi I, Chaieb M, Marmouche H, Aouni Z, Chaieb A, Mahjoub T, Vaxillaire M, Almawi WY: MTHFR C677T and Al298C Gene Polymorphisms and Hyperhomocysteinemia as Risk Factors of Diabetic Nephropathy in Type 2 Diabetes Patients. Diabetes Res Clin Pract 2007, 75(I):99-106.

38. Ezzidi I, Mtiraoui N, Kacem M, Mallat SG, Mohamed MB, Chaieb M, Mahjoub T, Almawi WY: Interleukin- 10 -592C/A, -8 I9C/T, and I 082A/G promoter variants affect the susceptibility to nephropathy in Tunisian type 2 diabetes patients. Clin Endocrinol 2009, 70(3):40I-7.

\section{Pre-publication history}

The pre-publication history for this paper can be accessed here: http://www.biomedcentral.com/1471-2350/10/33/pre pub
Publish with Bio Med Central and every scientist can read your work free of charge

"BioMed Central will be the most significant development for disseminating the results of biomedical research in our lifetime. "

Sir Paul Nurse, Cancer Research UK

Your research papers will be:

- available free of charge to the entire biomedical community

- peer reviewed and published immediately upon acceptance

- cited in PubMed and archived on PubMed Central

- yours - you keep the copyright

Submit your manuscript here:

http://www.biomedcentral.com/info/publishing_adv.asp
BiolMedcentral 